\title{
Sedentary behavior and health outcomes among older adults: a systematic review
}

\author{
Leandro Fornias Machado de Rezende ${ }^{1,2^{*}}$, Juan Pablo Rey-López ${ }^{1}$, Victor Keihan Rodrigues Matsudo² \\ and Olinda do Carmo Luiz ${ }^{1}$
}

\begin{abstract}
Background: In the last decade, sedentary behavior has emerged as a new risk factor for health. The elderly spend most of their awake time in sedentary activities. Despite this high exposure, the impact of this sedentary behavior on the health of this population has not yet been reviewed. We systematically reviewed evidence for associations between sedentary behavior and multiple health outcomes in adults over 60 years of age.

Methods: We searched the Medline, Embase, Web of Science, SPORTDiscus, PsycINFO, CINAHL, LILLACS, and Sedentary Research Database for observational studies published up to May 2013. Additionally, we contacted members of the Sedentary Behaviour Research Network to identify articles that were potentially eligible. After inclusion, the methodological quality of the evidence was assessed in each study.

Results: We included 24 eligible articles in our systematic review, of which only 2 (8\%) provided high-quality evidence. Greater sedentary time was related to an increased risk of all-cause mortality in the older adults. Some studies with a moderate quality of evidence indicated a relationship between sedentary behavior and metabolic syndrome, waist circumference, and overweightness/obesity. The findings for other outcomes such as mental health, renal cancer cells, and falls remain insufficient to draw conclusions.

Conclusion: This systematic review supports the relationship between sedentary behavior and mortality in older adults. Additional studies with high methodological quality are still needed to develop informed guidelines for addressing sedentary behavior in older adults.
\end{abstract}

Keywords: Sedentary lifestyle, Sitting time, Television, Risk factors, Aged, Health status, Mortality

\section{Background}

Globally, the older adult population has increased substantially, and it is estimated to reach approximately $22 \%$ of the world's population by 2050 [1,2]. The risk of noncommunicable diseases and disability increases with age, providing a challenge for health and social care resources [3]. The World Health Organization has created many recommendations for behavior change to reduce the burden of non-communicable diseases and disabilities among the elderly [4]. It is well established that physical activity plays a key role in the prevention of such diseases due to its close relationship with many of the chronic diseases

\footnotetext{
* Correspondence: lerezende@usp.br

'Department of Preventive Medicine, University of São Paulo School of Medicine, Av. Dr Arnaldo, 455 São Paulo, SP, Brazil

${ }^{2}$ Center of Studies and Physical Fitness Laboratory from São Caetano do Sul (CELAFISCS), Rua Heloisa Pamplona, 269 Bairro Fundação, São Caetano do
} Sul, SP, Brazil

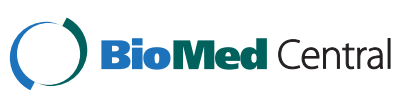

(C) 2014 Rezende et al.; licensee BioMed Central Ltd. This is an Open Access article distributed under the terms of the Creative Commons Attribution License (http://creativecommons.org/licenses/by/2.0), which permits unrestricted use, distribution, and reproduction in any medium, provided the original work is properly credited. The Creative Commons Public Domain Dedication waiver (http://creativecommons.org/publicdomain/zero/1.0/) applies to the data made available in this article unless otherwise stated. and disabilities that largely affect the elderly, such as cardiovascular disease, cancer, type 2 diabetes, accidental falls, obesity, metabolic syndrome, mental disorders, and musculoskeletal diseases [5,6].

However, in the last decade, sedentary behavior has emerged as a new risk factor for health [7-9]. Sedentary behaviors are characterized by any waking activity that requires an energy expenditure ranging from 1.0 to 1.5 basal metabolic rate and a sitting or reclining posture [10]. Typical sedentary behaviors are television viewing, computer use, and sitting time [10]. Epidemiological studies on different age groups show that a considerable amount of a human's waking hours are spent in sedentary activities, creating a new public health challenge that must be tackled $[11,12]$. The scientific study of sedentary behavior has become popular in recent years. In fact, several systematic reviews of sedentary behaviors and health outcomes among

rans 
children, adolescents, [13-15] and adults [11,16-19] have recently been published. However, insights from these systematic reviews are limited for several reasons. Firstly, some of these systematic reviews did not evaluate the quality of evidence of the reviewed articles $[17,16]$. Secondly, some reviews included subjects with a wide age range (i.e., $>18$ years) $[16,17]$. Therefore, it is currently assumed that the deleterious health effects attributed to sedentary behaviors are similar among both adults ( $>18$ years) and the elderly ( $>60$ years). However, it has been observed that some cardiovascular risk factors (i.e., smoking, obesity, and consumption of alcohol) are less predictive of mortality in a large sample of Scandinavians aged 75 years or older [20].

Furthermore, compared with other age groups, older adults are the most sedentary. Findings from studies in the US and Europe reported that objectively measured sedentary time was higher in those who were older than 50 years [12] and 65 years, [21] respectively. In addition, it has been reported that adults older than 60 years spend approximately $80 \%$ of their awake time in sedentary activities which represents 8 to 12 hours per day $[12,21,22]$. Similarly, Hallal et al. conducted a global assessment in more than 60 countries and found that the elderly had the highest prevalence of reporting a minimum of 4 hours of sitting time daily [23]. Despite this high exposure in the elderly, the health effects of sedentary behavior in this population have not yet been reviewed. Due to this knowledge gap, we systematically reviewed evidence to look for associations between sedentary behavior and multiple health outcomes in adults over 60 years of age.

\section{Methods}

\section{Identification and selection of the literature}

In May 2013, we searched the following databases: Medline, Excerpta Medica (EMBASE), Web of Science, SPORTDiscus, PsycINFO, Cumulative Index to Nursing and Allied Health Literature (CINAHL), Literatura Latino-Americana $e$ do Caribe em Ciências da Saúde (LILLACS), and the Sedentary Behavior Research Database (SBRD).

The key-words used were as follows: exposure (sedentary behavior, sedentary lifestyles, sitting time, television viewing, driving, screen-time, video game, and computer); primary outcome (mortality, cardiovascular disease, cancer, type 2 diabetes mellitus); and secondary outcome (accidental falls, frail elderly, obesity, metabolic syndrome, mental disorders, musculoskeletal diseases). Further information regarding the search strategy is included in Additional file 1. According to the purpose of this systematic review, observational studies (cross-sectional, case-control, or cohort) involving older adults (all participants $>60$ years), with no restriction of language or date, were selected in the screening step.
In addition, we contacted the Sedentary Behaviour Research Network (SBRN) members in July 2013 to request references related to sedentary behavior in older adults. The SBRN is a non-profit organization focused on the scientific network of sedentary behavior and health outcomes. Additional information about the SBRN can be found elsewhere (http://www.sedentarybehaviour.org/).

The studies retrieved were imported into the EndNote $\mathrm{Web}^{\circ}$ reference management software to remove any duplicates. Initially, titles and abstracts were screened by two independent reviewers (LFMR and JPRL). Relevant articles were selected for a full read of the article. Disagreements between the two reviewers were settled by a third reviewer. In addition, the reference lists of the relevant articles were reviewed to detect additional articles that were not identified in the previous search strategy.

Studies were excluded if they met the following criteria: 1) Included adults $<60$ years of age; 2) did not include physical activity as a covariate; or 3) presented only a descriptive analysis of sedentary behavior.

\section{Data extraction and quality assessment}

The data from all of the eligible articles were extracted independently by two reviewers (LFMR and JPRL). The extracted data included the following information: author(s), year, country, age group, number of participants, type of population (general or patient), type of sedentary behavior, type of measurement tool, sedentary definition, adjusted confounders, and outcome (Additional file 2: Table S1).

The quality assessment was performed by two independent reviewers (LFMR, JPRL) and discussed during a consensus meeting. The quality of articles was assessed using the Grades of Recommendation, Assessment, Development and Evaluation (GRADE) tool (Table 1). Briefly, the GRADE quality assessment tool begins with the design of the study. Studies with an observational design start with a low quality ( 2 points). The studies then lose points based on the presence of the following topics: risk of bias ( -1 or -2 points), imprecision ( -1 or -2 points), inconsistency ( -1 or -2 points), and indirectness (surrogate outcome) ( -1 or -2 points). However, studies gain points if the following criteria are met: a high magnitude of effect (RR $2-5$ or $0.5-0.2)$ (+ 1 or 2 points), adequate confounding adjustment ( +1 point), and a dose-response relationship ( +1 point). Finally, the quality of the articles is categorized as follows: high (4 points), moderate (3 points), low ( 2 points), or very low (1 point). Further information about GRADE has been published elsewhere [24].

\section{Results}

\section{Search and selection}

The search included 10874 potentially relevant articles (1301 from Medline, 5190 from EMBASE, 2803 from Web of Science, 184 from CINAHL, 160 from Lillacs, 
Table 1 Quality of articles assessed using the Grades of Recommendation, Assessment, Development and Evaluation (GRADE)

\begin{tabular}{|c|c|c|c|c|c|c|c|c|c|c|}
\hline Author & Year & Design & Bias & Imprecision & Indirectness & Heterogeneity & $\begin{array}{c}\text { Magnitude } \\
\text { of effect }\end{array}$ & $\begin{array}{c}\text { Confounding } \\
\text { adjustment }\end{array}$ & $\begin{array}{c}\text { Dose- } \\
\text { response }\end{array}$ & Rating \\
\hline Gardiner et al. [25] & 2011 & Cross-sectional & -1 & -1 & -1 & -1 & 0 & 1 & 0 & 1 \\
\hline Lynch et al. [26] & 2011 & Cross-sectional & -1 & -1 & -1 & 0 & 0 & 1 & 0 & 1 \\
\hline George et al. [27] & 2011 & Cross-sectional & 2 & -1 & -1 & 0 & 0 & 1 & 0 & 3 \\
\hline $\begin{array}{l}\text { Stamatakis } \\
\text { et al. [28] }\end{array}$ & 2012 & Cross-sectional & -1 & 0 & -1 & 0 & 0 & 1 & 0 & 1 \\
\hline Frank et al. [29] & 2010 & Cross-sectional & -2 & -1 & -1 & 0 & 0 & 1 & 0 & 1 \\
\hline $\begin{array}{l}\text { Gomez-Cabello } \\
\text { et al. [30] }\end{array}$ & 2012 & Cross-sectional & -1 & -1 & -1 & 0 & 1 & 0 & 0 & 1 \\
\hline $\begin{array}{l}\text { Gomez-Cabello } \\
\text { et al. [31] }\end{array}$ & 2012 & Cross-sectional & -1 & -1 & -1 & 0 & 0 & 0 & 0 & 1 \\
\hline Buman et al. [32] & 2010 & Cross-sectional & -2 & 0 & -1 & 0 & 0 & 1 & 0 & 1 \\
\hline Hamer et al. [33] & 2012 & Cross-sectional & -2 & 0 & -1 & 0 & 0 & 1 & 0 & 1 \\
\hline Hamer et al. [34] & 2012 & Cross-sectional & -2 & -1 & -1 & 0 & 0 & 1 & 0 & 1 \\
\hline Bankoski et al. [35] & 2011 & Cross-sectional & 0 & -1 & -1 & 0 & 0 & 1 & 0 & 1 \\
\hline Gao et al. [36] & 2007 & Cross-sectional & 0 & -1 & -1 & 0 & 1 & 1 & 1 & 3 \\
\hline Inoue et al. [37] & 2012 & Cross-sectional & -2 & -1 & -1 & 0 & 0 & 1 & 0 & 1 \\
\hline Dogra et al. [38] & 2012 & Cross-sectional & -1 & -1 & 0 & 0 & 1 & 1 & 0 & 2 \\
\hline Gennuso et al. [39] & 2013 & Cross-sectional & 0 & -1 & -1 & 0 & 1 & 1 & 1 & 3 \\
\hline Geda et al. [40] & 2011 & Cross-sectional & -1 & 0 & -1 & 0 & 1 & 1 & 0 & 2 \\
\hline Geda et al. [41] & 2012 & Case-control & -1 & -1 & -1 & 0 & 1 & 0 & 0 & 1 \\
\hline $\begin{array}{l}\text { Balboa-Castillo } \\
\text { et al. [42] }\end{array}$ & 2011 & Prospective Cohort & -2 & -1 & 0 & 0 & 1 & 1 & 1 & 2 \\
\hline Campbell et al. [43] & 2013 & Prospective Cohort & -1 & 0 & 0 & 0 & 0 & 1 & 0 & 2 \\
\hline $\begin{array}{l}\text { Martinez-Gomez } \\
\text { et al. [44] }\end{array}$ & 2013 & Prospective Cohort & -1 & 0 & 0 & 0 & 1 & 1 & 0 & 3 \\
\hline Pavey et al. [45] & 2012 & Prospective Cohort & -1 & 0 & 0 & 0 & 1 & 1 & 1 & 4 \\
\hline $\begin{array}{l}\text { León-Muñoz } \\
\text { et al. [46] }\end{array}$ & 2013 & Prospective Cohort & -1 & 0 & 0 & 0 & 1 & 1 & 1 & 4 \\
\hline Verghese et al. [47] & 2003 & Prospective Cohort & -2 & 0 & 0 & 0 & 1 & 1 & 0 & 2 \\
\hline
\end{tabular}

154 from SportsDiscus, 936 from PsychInfo, and 146 from Sedentary Behavior Research Database). Fourteen additional records were selected from the articles suggested by the SBRN members (Figure 1).

After removing duplicate records, a total of 9768 articles remained. After screening titles and abstracts, 56 full papers were read in their entirety. In addition, 2 articles were found in the reference list of these full papers (an additional 787 titles were screened). Of the 58 articles, only 23 met the inclusion criteria and were included in the review. The complete list of included and excluded articles is presented in the Additional file 3.

\section{Methodological quality assessment}

Additional file 2: Table S1 presents the quality assessment of the 23 articles included in the review. Of the 23 articles included, 16 (70\%) were cross-sectional studies, [25-40] 1 (4\%) was a case-control study, [41] and 6 (26\%) were prospective cohort studies [42-47]. Concerning quality of the evidence, 12 (52\%) were evaluated as very low, [25,26,29-36,38,42] $5(22 \%)$ as low, [39,41,43,44,48] 4 $(17 \%)$ as moderate, $[28,37,40,45]$ and $2(9 \%)$ as high quality evidence $[46,47]$.

Risk of selection bias was identified in 9 articles (39\%), $[25,28,29,31-34,37,42,47]$ and information bias due to selfreported instruments was found in 20 articles (83\%) [25-27,31-34,37,38,40-47]. Indirectness (surrogate outcomes) was used in 16 articles (70\%), [25-37,39-41] imprecise results were presented in 14 (61\%) articles, [25-27, 30-32,34-39,41,42] and an inconsistent [25] result among subgroups was found in $1(4 \%)$ article. Most of the articles $(\mathrm{n}=20-87 \%)$ received an additional point for the adjustment of potential confounders [25-29,32-39,41-47]. Eleven (48\%) studies gained a point for magnitude of effect [30,36,39,8-42,44-47] and 5 (22\%) for considering a doseresponse relationship [36,39,42,45,46]. Further details 


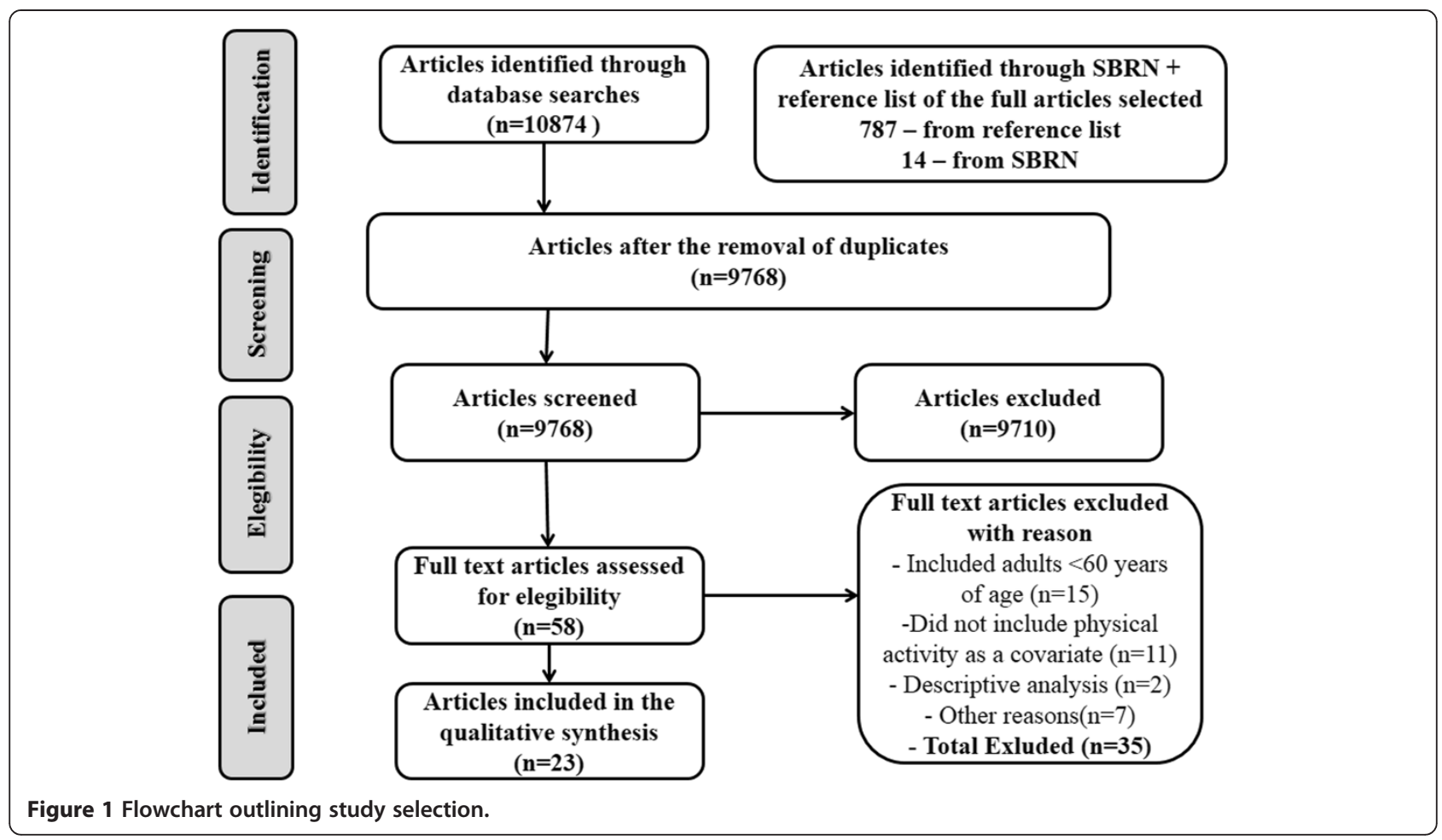

concerning the quality assessment of each article are presented in the Additional file 4.

\section{Sedentary behavior-health outcomes Mortality}

Four prospective cohort studies, [43-46] classified as low, [43] moderate [44] and high quality, [45,46] investigated the relationship between sedentary behavior and mortality (all-cause, cardiovascular, colorectal cancer, other causes).

Martinez-Gomez et al.'s [44] study showed that individuals who spent less than 8 hours sitting/day had a lower risk of all-cause mortality ( $\mathrm{HR}=0.70,95 \% \mathrm{CI}$ : 0.60 to 0.82 ) when compared with their sedentary peers. In addition, individuals who were physically active and less sedentary ( $<8$ hours/day of sitting) showed a lower risk of all causemortality (HR 0.44; $95 \%$ CI: 0.36 to 0.52 ) than those who were inactive and sedentary.

Similarly, Pavey et al. [45] found a dose-response relationship between sitting time and all-cause mortality. Individuals who spent $8-11$ hours/day (HR 1.35; 95\% CI $1.09-1.66)$ and more than 11 hours/day sitting (HR 1.52 ; $95 \%$ CI 1.17 - 1.98) presented a higher risk of allcause mortality than those who spent less than 8 hours/ day sitting. For each hour/day spent sitting, there was an increase of 3\% (HR 1.03; CI 95\% 1.01-1.05) in the risk of all-cause mortality. Moreover, the risk of all-cause mortality of individuals who were physically inactive (less than 150 minutes/week) and spent 8-11 or more than 11 hours/ day sitting increased by $31 \%$ (HR 1.31, 95\% CI 1.07 to 1.61 ) and $47 \%$ (HR 1.47, CI 1.15 to 1.93 ), respectively.

In León-Munoz et al., [46] individuals were classified as consistently sedentary (>median in 2001 and 2003), newly sedentary (<median in 2001 and $>$ median in 2003), formerly sedentary (>median in 2001 and $<$ median in 2003), and consistently nonsedentary (<median in 2001 and 2003). They found that when compared with the consistently sedentary group, subjects newly sedentary (HR 0.91 ; $95 \%$ CI 0.76 - 1.10), formerly sedentary $(0.86 ; 95 \%$ CI $0.70-1.05)$, or consistently non-sedentary $(0.75 ; 95 \% \mathrm{CI}$ $0.62-0.90)$ were protective against all-cause mortality.

Examining a colorectal cancer survivor population, Campbell et al. [43] identified that more than 6 hours per day of pre-diagnosis leisure sitting time, when compared with fewer than 3 hours per day, was associated with a higher risk of all-cause mortality (RR, 1.36; 95\% CI, 1.10 to 1.68) and mortality from all other causes (not cardiovascular and colorectal cancer) (RR, 1.48; 95\% CI 1.05-2.08). Post-diagnosis (colon cancer) sitting time ( $>6$ hours) was associated with a higher risk of all-cause mortality (RR, 1.27; $95 \%$ CI, 0.99 to 1.64 ) and colorectal cancer-specific mortality (RR, 1.62; 95\% CI, 1.07-2.44).

\section{Metabolic syndrome}

Three cross-sectional studies, [25,35,36] classified as very low [25,35] and moderate [36] quality, investigated the relationship between sedentary behavior and metabolic syndrome. 
Gardiner et al., [25] showed that individuals who spent most of their time sitting (highest quartile, $>3$ hours/day) had an increased odds of having metabolic syndrome (men: OR 1.57; CI 95\% 1.02 - 2.41 and women: OR 1.56; CI 95\% 1.09 - 2.24) when compared with their less sedentary peers (lowest quartile, $<1.14$ hours/day). In the same study, women who watched more television (highest quartile) increased their risk of metabolic syndrome by $42 \%$ (OR 1.42; CI 95\% 1.01 - 2.01) when compared with those who watched less television per day (lowest quartile).

In the same sense, Gao et al. [36] showed that individuals in the highest quartile ( $>7$ hours/day) of television watching/day, when compared with those in the lowest quartile ( $<1$ hours/day), had an increased odds (OR 2.2, 95\% CI 1.1-4.2) of having metabolic syndrome. In a doseresponse relationship, for each hour of television watching/day, there was an increase of $19 \%$ in the odds (95\% CI 1.1-1.3; p for trend 0.002) of having metabolic syndrome.

Bankoski et al. [35] found that a greater percentage of the time spent in sedentary behavior increased the risk of having metabolic syndrome (only quartile 2 vs. quartile 1, the hours/day of each quartile was not reported; OR 1.58; $95 \%$ CI 1.03 - 2.24), whereas breaks in sedentary time throughout the day protected against metabolic syndrome (only quartile 2 vs. quartile 1; OR 1.53; 95\% CI 1.05 - 2.23).

\section{Cardiometabolic biomarkers}

Six cross-sectional studies, [25,28,33,34,36,39] classified as of very low [25,28,33,34] and of moderate quality, [36,39] investigated the relationship between sedentary behavior and independent cardiometabolic biomarkers.

\section{Triglycerides}

The likelihood of having high triglycerides was higher in men (Odds Ratio (OR) 1.61; 95\% CI 1.01-2.58) and women (OR 1.66; 95\% CI 1.14-2.41) who were in the highest quartile of overall sitting time [25]. However, Gao et al. [36] and Gennuso et al. [39] showed that the association between time spent in sedentary behavior and high triglycerides was not statistically significant.

\section{HDL cholesterol}

Gao et al., [36] found that greater time spent viewing television was associated with low HDL cholesterol (2.5; 95\% CI 1.0-5.9; p < 0.05). In a study by Gardiner et al., [25] women in the highest quartile of television viewing and men in the highest quartile of overall sitting time presented an OR for low HDL cholesterol of 1.64 (95\% CI 1.06-2.54) and 1.78 (95\% CI 1.78; 95\% CI 1.05-3.02), when compared with the lowest quartile, respectively. However, Gennuso et al. [39] found that the relationship between time spent in sedentary behavior and low HDL cholesterol was not statistically significant $(\mathrm{p}=0.29)$.

\section{Blood pressure}

When compared with the lowest quartile of overall sitting time, the OR for high blood pressure in the third quartile was 1.50 (95\% CI 1.03-2.19) [25]. In Gao et al.'s [36] study, greater time viewing television was associated with high blood pressure $(2.5 ; 95 \%$ CI 1.0-6.0; $\mathrm{p}<0.05)$. However, Gennuso et al. [39] found that the relationship between time spent in sedentary behavior and systolic blood pressure $(\mathrm{p}=0.09)$ and diastolic blood pressure $(\mathrm{p}=0.32)$ was not statistically significant.

\section{Plasma Glucose/ Hb1 Ac/ Glucose intolerance}

Gennuso et al. [39] demonstrated that greater television viewing and sedentary time was associated with higher plasma glucose $(p=0.04)$. In Gardiner et al.'s [25] study, this relationship was observed only in women $(1.45$; $95 \%$ CI 1.01-2.09; p < 0.05). However, Gao et al. [36] and Stamatakis et al. [28] found that the relationship between television viewing and high fasting glucose and Hb1Ac was not statistically significant.

\section{Cholesterol ratio and total}

Gao et al. [36] demonstrated that greater time in television viewing was associated with a high total-to-HDL cholesterol ratio (OR 2.0; 95\% CI 1.1-3.7; p < 0.05). In Stamatakis et al.'s [28] study, self-reported total leisure-time sedentary behavior ( $\beta$ 0.018; 95\% CI 0.005-0.032), television viewing ( $\beta$ 0.021; 95\% CI 0.002-0.040), and objectively assessed sedentary behavior ( $\beta$ 0.060; 95\% CI 0.000-0.121) were associated with cholesterol ratio. However, Gennuso et al. [39] found that the relationship between time spent in sedentary behavior and total cholesterol was not statistically significant $(\mathrm{p}=0.50)$.

\section{Other cardiometabolic biomarkers}

The association between objectively measured sedentary time and pericardial fat [33] and coronary artery calcification [34] was not observed after adjusting for moderate to vigorous physical activity. Gennuso et al. [39] found a positive association between sedentary hours and C-reactive protein $(\mathrm{p}<0.01)$.

\section{Waist circumference/waist-to-hip ratio/abdominal obesity}

Six cross-sectional studies, [25,26,28,30,36,39] classified as being of very low $[25,26,28,30]$ and of moderate $[36,39]$ quality, investigated the relationship between sedentary behavior and waist circumference/waist-to-hip/abdominal obesity.

Gardiner et al. [25] and Gomez-Cabello et al. [30] found that sitting time increased the risk of abdominal obesity by 80\% (OR 1.8; 95\% CI 1.20-2.64) in both sexes and $81 \%$ in women (OR 1.81; 95\% CI 1.21-2.70).

In Stamatakis et al.'s [28] study, television time ( $\beta$ 0.416; 95\% CI 0.275 - 0.558) and total self-reported leisure-time 
sedentary behavior ( $\beta$ 0.234; 95\% CI 0.129 - 0.339) were positively related to waist circumference. Gao et al. [36] found that greater time in television viewing was associated with high waist-to-hip ratio $(3.9 ; 95 \%$ CI 1.08 - 8.4; $\mathrm{p}<0.01)$. Gennuso et al. [39] found that more time spent in objectively measured sedentary behavior was associated with a high waist circumference $(\mathrm{p}<0.01)$. In a colorectal cancer survivor population, [26] sedentary time was not associated with waist circumference.

\section{Overweight/obesity}

Six cross-sectional studies, [28-31,36,37,39] classified as being of very low [28-31,37] and of moderate [36,39] quality, investigated the relationship between sedentary behavior and overweight/obesity.

Gomez-Cabello et al. [30] demonstrated that sitting more than 4 hours/day increased the risk of overweight (OR 1.7; 95\% CI 1.06-2.82) and obesity (OR 2.7; 95\% CI 1.62-4.66). In a similar study, Gomez-Cabello et al. [31] showed that being seated more than 4 hours/day increased the risk of overweight/obesity (OR 1.42; 95\% CI 1.06-1.89) and overfat (1.4 OR; 95\% CI 1.14-1.74) in women and the risk of central obesity (OR 1.74; 95\% CI 1.21 - 2.49) in men.

Gennuso et al. [39] found that more time spent in objectively measured sedentary behavior was associated with higher BMI $(\mathrm{p}<0.01)$. In Stamatakis et al.'s [28] study, self-reported leisure-time sedentary behavior ( $\beta$ 0.088; 95\% CI 0.047 - 0.130) was associated with BMI.

Inoue et al. [37] found that when compared with the reference category (high television(TV)/insufficient moderate to vigorous physical activity (MVPA)), the adjusted ORs (95\% CI) of overweight/obesity were 0.93 (95\% CI 0.65 1.34) for high TV/sufficient MVPA, 0.58 (95\% CI 0.37 0.90 ) for low TV/insufficient MVPA, and 0.67 (95\% CI 0.47-0.97) for low TV/sufficient MVPA. Stamatakis et al. [28] also showed that TV time ( $\beta$ 0.159; 95\% CI 0.1040.215 ) was positively associated with BMI. However, only Gao et al. [36] found that greater time of television viewing was statistically significantly association with BMI (OR $1.4 ; 95 \% 0.7-2.8)$.

In the only study that evaluated sedentary behavior in transport, Frank et al. [29] showed that $\geq 1$ hour/day sitting in cars was not associated with overweight (0.86 OR. 95\% CI 0.51-1.22) or obesity (0.67 OR; 95 CI\% 0.41-1.06).

\section{Mental health (Dementia, mild cognitive impairment, psychological well-being)}

Three cross-sectional studies, [32,38,40] one case-control, [41] and two prospective cohort studies, $[42,47]$ classified as very low $[32,41]$ and low quality $[38,40,42,47]$ investigated the relationship between sedentary behavior and mental health (dementia, mild cognitive impairment, and psychological well-being).
In Verghese et al.'s [47] study, individuals who frequently played board games (HR 0.26; 95\% CI 0.17-0.57) and read (HR 0.65 ; 95\% CI 0.43-0.97) were less likely to develop dementia.

Buman et al. [32] demonstrated that sedentary time was negatively associated with psychosocial well-being $(\beta-0.03 ; 95 \%$ CI $-0.05-0.01) ; \mathrm{p}<0.001$. However, Dogra et al. [38] found that 4 hours or more of sedentary behavior per day was not associated with psychologically successful aging.

With regards to mild-cognitive impairment (MCI), reading books (OR 0.67; 95\% CI 0.49-0.94), playing board games (OR 0.65; 95\% CI 0.47-0.90), craft activities (OR 0.66; 95\% CI 0.47-0.93), computer activities (OR 0.50 ; 95\% CI 0.36-0.71), and watching television (OR 0.48; 95\% CI 0.27-0.86) were significantly associated with a decreased odds of having MCI [40]. According to Geda et al.'s [41] study, physical exercise and computer use were associated with a decreased likelihood of having MCI (OR 0.36; CI 95\% 0.20-0.68).

However, Balboa-Castillo et al. [42] found that the highest quartile of sitting time was negatively associated with mental health $(\beta-5.04 ; 95 \%$ CI $-8.87--1.21)$; $\mathrm{p}$ trend $=0.009$.

\section{Cancer}

Only one study, with moderate quality, found no association between time watching television or videos and renal cell carcinoma [27].

\section{Discussion}

To the best of our knowledge, this is the first systematic review to examine the association between sedentary behavior and health outcomes in older people while considering the methodological quality of the reviewed studies. Similar to previous reviews in adults, [16-19,48] the present review shows observational evidence that greater time spent in sedentary activities is related to an increase risk of all-cause mortality in the elderly. However, in these studies, sedentary behavior was measured through self-reported questionnaires (e.g., hours/day of sitting time), which have moderate criterion validity [49]. Studies with a moderate quality of evidence showed a relationship between sedentary behavior and metabolic syndrome, waist circumference, and overweight/obesity. The findings for other outcomes, such as mental health, renal cancer cells, and falls, remain insufficient to draw conclusions.

However, some sedentary activities (e.g., playing board games, craft activities, reading, computer use) were associated with a lower risk of dementia [47]. Thus, future studies should take into account not only the amount of time spent in sedentary behavior but the social and cognitive context in which the activities takes place [50]. To 
illustrate this point, some studies have shown that video game and computer use, even though classified as sedentary by energy expenditure criteria, may reduce the risk of mental health disorders [51-53].

\section{Methodological issues}

To overcome the limitations of the observational studies available, future longitudinal studies with a high methodological quality are required. Moreover, the primary limitations found in the reviewed articles should be taken into account in future studies (Additional file 4). Based on these limitations, we offer several recommendations for future studies.

\section{Selection bias}

In nearly half of the reviewed articles (10 articles: 42\%), the following selection biases were found: a low response rate; the use of independent and non-institutionalized volunteer participants; and an underrepresentation of some population subgroups [25,27-29,31-34,37,41,47].

\section{Information bias}

To date, the use of accelerometers is the most valid and reliable method for evaluating sedentary behavior, although some devices are not able to distinguish sitting and standing posture [54]. In studies of the elderly, 5 days of accelerometer use seems to be sufficient to evaluate the pattern of sedentary behavior [55]. When using accelerometers, future studies should clearly specify the criteria established for non-wear time [56] and use the most accurate sedentary cut-points (150 counts/min) [57] to avoid misclassification. In the current review, all studies used at least 7 days of accelerometry, with a non-wear time criteria of 60 minutes without counts and sedentary cutpoints of $<100$ counts/minute $[26,28,32,37,39]$ or $<199$ counts/minute [33,34].

Although subjective measurements present a low to moderate reliability, they allow for the evaluation of the contextual dimension of the sedentary activities [49]. In the present review, information bias attributable to selfreported instruments was found in 20 articles (83\%) [25-27,29-34,37,38,42-44,40,41,45-47]. In this sense, emergent objective methods (e.g., combination of geolocation data combined with acceleration signals in mobile phone) have been developed to obtain a precise and meaningful characteristic of the patterns of sedentary behavior [49].

In addition, most of the studies in this review used different categorization criteria when measuring sedentary behavior [43-46]. This variation in categorization criteria could limit future synthesis of the evidence. We recommend that future studies on the elderly use existing categorizations of sedentary behavior.

\section{Imprecision}

To reduce random error, future epidemiological studies, especially with longitudinal designs, should use an adequate sample size. In the present review, 14 (58\%) studies presented imprecise results [25-27,29-31,34-39,41,42].

\section{Inconsistency}

Subgroup and heterogeneity analysis should be performed and reported in future studies to evaluate the consistency of the findings. In the current study, only one article presented the consistency of the findings between subgroups [25].

Indirectness: In the current review, indirectness (surrogate outcomes) was present in 17 articles (71\%) [25-37,39-41]. Importantly, conclusions obtained with surrogate markers only allow a better understanding of the sedentary behavior physiology. However, researchers should not consider these surrogate markers as synonymous with the endpoint outcomes [58].

Thus, endpoint outcomes (e.g., cardiovascular events, cancer and mortality) should be addressed in future studies.

\section{Confounding adjustment}

The confusion of effects (confounding) is a central issue in epidemiology. Although all of the studies in the present review included some covariates, such as moderate to vigorous physical activity, some residual confounding may be present [59]. Moreover, health status should be measured and included as a covariate, especially in studies of the elderly to avoid confounding [59]. Although most of the articles received better quality scores when they adjusted for potential confounders, [25-29,32-40,42-47] only 3 studies included health status as a covariate $[25,45,46]$. Future observational studies should include these important covariates in their statistical analysis.

\section{Dose-response}

Although sedentary behavior is a continuous variable, most of the studies categorized it as either an ordinal or a dummy variable. Such categorization could be an important limitation $[60,61]$. However, if future studies opt to categorize, they should use small intervals with more homogeneous groups that may allow for the observation of a dose-response gradient between sedentary behavior and health outcomes. In the present review, a dose-response was detected in 5 articles [36,39,42,45,46].

\section{Conclusion}

This review confirms previous evidence of the relationship between sedentary behavior and all-cause mortality among adults. Due to the moderate quality of the studies, weak evidence exists regarding other health outcomes (metabolic syndrome, cardiometabolic biomarkers, obesity, and 
waist circumference). However, of note, some sedentary activities (e.g., playing board games, craft activities, reading, and computer use) had a protective relationship with mental health status (dementia). Future studies should consider the main methodological limitations summarized in this review to improve the current state of the art. Finally, intervention trials that support the observational knowledge are needed to create informed guidelines for sedentary behavior in the elderly.

\section{Additional files}

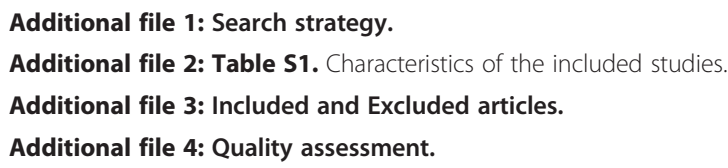

\section{Abbreviations}

EMBASE: Excerpta Medica; CINAHL: Cumulative Index to Nursing and Allied Health Literature (CINAHL); LILACS: Literatura Latino-Americana e do Caribe em Ciências da Saúde; SBRD: and the Sedentary Behavior Research Database (SBRD); SBRN: Sedentary Behaviour Research Network; GRADE: Grades of Recommendation; Assessment: Development and Evaluation; HR: Hazard Ratio; RR: Relative Risk; OR: Odds Ratio; HDL: High Density Lipoprotein; MVPA: Moderate to vigorous physical activity; TV: Television; BMI: Body mass index; MCl: Mild-cognitive impairment.

\section{Competing interests}

No financial disclosures were reported by the authors of this paper.

\section{Authors' contributions}

Study Concept and design: LFMR, OCL; Search Strategy: LFMR; Identification and Selection of the Literature: LFMR, JPRL; Data Extraction and Quality Assessment: LFMR, JPRL; Narrative Synthesis: LFMR, JPRL; Drafting of the Manuscript: LFMR, JPRL; Study Supervision: OCL, VKRM. All authors read and approved the final manuscript.

\section{Authors' information}

LFMR is a master's student in the Department of Preventive Medicine University of São Paulo School of Medicine. JPRL is a post-doctoral student in the Department of Preventive Medicine - University of São Paulo School of Medicine. VKRM is a scientific coordinator of CELAFISCS. OCL is a scientific researcher in the Department of Preventive Medicine - University of São Paulo School of Medicine.

\section{Acknowledgements}

We would like to thank the Sedentary Behaviour Research Network members for sending us titles of studies that were potentially eligible for inclusion in our systematic review. This study received financial support from the Fundação de Amparo à Pesquisa do Estado de São Paulo (FAPESP, São Paulo Research Foundation; Grant no. 2012/07314-8).

Received: 8 November 2013 Accepted: 31 March 2014 Published: 9 April 2014

\section{References}

1. Scully T: Demography: to the limit. Nature 2013, 492:S2-S3. doi:10.1038/492S2a

2. WHO: Global Age-friendly Cities: A Guide. Geneva: WHO press; 2007.

3. Federal Interagency Forum on Aging-Related Statistics: Older Americans 2012: Key Indicators of Well-Being. Washington, DC: U.S: Federal Interagency Forum on Aging-Related Statistics; 2012.

4. WHO: Good Health Adds Life to Years: Global Brief for World Health Day 2012. Geneva: WHO press; 2012.

5. WHO: Global Recommendations on Physical Activity for Health. Geneva: WHO press; 2010 .
6. Dishman RK, Health GW, Lee IM: Physical Activity Epidemiology. 2nd edition. Champaign, IL: Human Kinetics; 2013.

7. Katzmarzyk PT: Physical activity, sedentary behavior, and health: paradigm paralysis or paradigm shift? Diabetes 2010, 59:2717-2725.

8. Owen N: Sedentary behavior: understanding and influencing adult's prolonged sitting time. Prev Med 2012, 55:535-539.

9. Owen N, Healy GN, Matthews CE, Dustan DW: Too much sitting: the population health science of sedentary behavior. Exerc Sport Sci Rev 2010, 38:105-113.

10. Pate RR, O'Neill JR, Lobelo F: The evolving definition of "sedentary". Exerc Sport Sci Rev 2008, 36:173-178.

11. Rhodes RE, Mark RS, Temmel CP: Adult sedentary behavior a systematic review. Am J Prev Med 2012, 42:E3-E28.

12. Matthews CE, Chen KY, Freedson PS, Buchowski MS, Beech BM, Pate RR, Troiano RP: Amount of time spent in sedentary behaviors in the United States, 2003-2004. Am J Epidemiol 2008, 167:875-881.

13. LeBlanc AG, Spence JC, Carson V, Connor Gorber S, Dillman C, Janssen I, Kho ME, Stearns JA, Timmons BW, Tremblay MS: Systematic review of sedentary behaviour and health indicators in the early years (aged 0-4 years). Appl Physiol Nutr Metab 2012, 37:753-772.

14. Tremblay MS, LeBlanc AG, Kho ME, Saunders TJ, Larouche R, Colley RC, Goldfield G, Connor Gorber S: Systematic review of sedentary behaviour and health indicators in school-aged children and youth. Int J Behav Nutr Phys Act 2011, 8:98.

15. Marshall SJ1, Biddle SJ, Gorely T, Cameron N, Murdey I: Relationships between media use, body fatness and physical activity in children and youth: A meta-analysis. Int J Obesity 2004, 28:1238-1246.

16. Thorp AA, Owen N, Neuhaus M, Dustan DW: Sedentary behaviors and subsequent health outcomes in adults a systematic review of longitudinal studies, 1996-2011. Am J Prev Med 2011, 41:207-215.

17. Grontved A, Hu FB: Television viewing and risk of type 2 diabetes, cardiovascular disease, and all-cause mortality A Meta-analysis. JAMA 2011, 305:2448-2455

18. Wilmot EG, Edwardson CL, Achana FA, Davies MJ, Gorely T, Gray LJ, Khunti K, Yates T, Biddle SJ: Sedentary time in adults and the association with diabetes, cardiovascular disease and death: systematic review and meta-analysis. Diabetologia 2012, 55:2895-2905

19. Lynch BM: Sedentary behavior and cancer: a systematic review of the literature and proposed biological mechanisms. Cancer Epidemiol Biomarkers Prev 2010, 19:2691-2709.

20. Nybo H, Petersen HC, Gaist D, Jeune B, Andersen K, McGue M, Vaupel JW, Christensen K: Predictors of mortality in 2,249 nonagenarians - the Danish 1905-Cohort Survey. J Am Geriatr Soc 2003, 51:1365-1373.

21. Davis MG, Fox KR, Hillsdon M, Sharp DJ, Coulson JC, Thompson Lال Objectively measured physical activity in a diverse sample of older urban UK adults. Med Sci Sports Exerc 2001, 43:647-654.

22. McLennan W, Podger A: National nutrition survey users' guide. In Catalogue No 48010. Canberra, ACT: Australian Bureau of Statistics; 1998.

23. Hallal PC, Andersen LB, Bull FC, Guthold R, Haskell W, Ekelund U: Global physical activity levels: surveillance progress, pitfalls, and prospects. Lancet 2012, 380:247-257.

24. Guyatt GH, Oxman AD, Schünemann HJ, Tugwell P, Knotterus A: GRADE guidelines: A new series of articles in the Journal of Clinical Epidemiology. J Clin Epidemiol 2011, 64:380-382.

25. Gardiner PA, Healy GN, Eakin EG, Clark BK, Dunstan DW, Shaw JE, Zimmet PZ, Owen N: Associations between television viewing time and overall sitting time with the metabolic syndrome in older men and women: the Australian Diabetes, Obesity and Lifestyle study. J Am Geriatr Soc 2011, 59:788-796.

26. Lynch BM, Dunstan DW, Winkler E, Healy GN, Eakin E, Owen N: Objectively assessed physical activity, sedentary time and waist circumference among prostate cancer survivors: findings from the National Health and Nutrition Examination Survey (2003-2006). Eur J Cancer Care 2011, 20:514-519.

27. George SM, Moore SC, Chow WH, Schatzkin A, Hollenbeck AR, Matthews CE: A prospective analysis of prolonged sitting time and risk of renal cell carcinoma among 300,000 older adults. Ann Epidemiol 2011, 21:787-790.

28. Stamatakis E, Davis M, Stathi A, Hamer M: Associations between multiple indicators of objectively-measured and self-reported sedentary behaviour and cardiometabolic risk in older adults. Prev Med 2012, 54:82-87.

29. Frank L, Keer J, Rosenberg D, King A: Healthy aging and where you live: community design relationships with physical activity and body weight in older Americans. J Phys Act Health 2010, 7(Suppl 1):S82-S90. 
30. Gomez-Cabello A, Vicente-Rodriguez G, Pindado M, Vila S, Casajús JA, Pradas Dela Fuente F, Ara I: Increased risk of Obesity and central obesity in sedentary postmenopausal Women. Nutr Hosp 2012, 27:865-870.

31. Gomez-Cabello A, Pedreto-Chamizo R, Olivares PR, Hernández_Perera R, Rodríguez-Marroyo JA, Mata E, Aznar S, Villa JG, Espino-Torón L, Gusi N, González G, Casajús JA, Ara I, Vicente-Rodríguez G: Sitting time increases the overweight and obesity risk independently of walking time in elderly people from Spain. Maturitas 2012, 73:337-343.

32. Buman MP, Hekler EB, Haskell WL, Pruitt L, Conway $T L$, Cain $K L$, Sallis JF, Saelens BE, Frank LD, King AC: Objective light-intensity physical activity associations with rated health in older adults. Am J Epidemio/ 2010, 172:1155-1165.

33. Hamer M, Venuraju SM, Urbanova L, Lahiri A, Steptoe A: Physical activity, sedentary time, and pericardial fat in healthy older adults. Obesity 2012, 20:2113-2117.

34. Hamer M, Venuraju SM, Lahiri A, Rossi A, Steptoe A: Objectively assessed physical activity, sedentary time, and coronary artery calcification in healthy older adults. Artriolscler Thromb Vasc Biol 2012, 32:500-505.

35. Bankoski A, Harris TB, McClain JJ, Brychta RJ, Caserotti P, Chen KY, Berrigan D, Troiano RP, Koster A: Sedentary activity associated with metabolic syndrome independent of physical activity. Diabetes Care 2011, 34:497-503.

36. Gao X, Nelson ME, Tucker KL: Television viewing is associated with prevalence of metabolic syndrome in hispanic elders. Diabetes Care 2007, 30:694-700

37. Inoue S, Sugiyama T, Takamiya T, Oka K, Owen N, Shimomitsu T: Television viewing time is associated with overweight/obesity among older adults, independent of meeting physical activity and health guidelines. J Epidemiol 2012, 22:50-56.

38. Dogra S, Stathokostas L: Sedentary behavior and physical activity are independent predictors of sucessful aging in middle-aged and older adults. Aging Res 2012, 2012:190654.

39. Gennuso KP, Gangnon RE, Matthews CE, Thraen-Borowski KM, Colbert LH: Sedentary behavior, physical activity, and markers of health in older adults. Med Sci Sports Exerc 2013, 45:1493.

40. Geda YE, Topazian HM, Roberts LA, Roberts RO, Knopman DS, Pankratz VS, Christianson TJ, Boeve BF, Tangalos EG, Ivnik RJ, Petersen RC: Engaging in cognitive activities, aging, and mild cognitive impairment: a population based study. J Neuropsychiatry Clin Neurosci 2011, 23:149-154.

41. Geda F, Silber TC, Roberts RO, Knopman DS, Christianson TJ, Pankratz VS, Boeve BF, Tangalos EG, Petersen RC: Computer activities, physical exercise, aging, and mild cognitive impairment: a population-based study. Mayo Clin Proc 2012, 87:437-442.

42. Balboa-Castillo T, León-Munoz LM, Graciani A, Rodríguez-Artalejo F, GuallarCastillón P: Longitudinal association of physical activity and sedentary behavior during leisure time with health-related quality of life in community-dwelling older adults. Health Qual Life Outcomes 2011, 27:9-47.

43. Campbell PT, Patel AV, Newton CC, Jacobs EJ, Gapstur SM: Associations of recreational physical activity and leisure time spent sitting with colorectal cancer survival. J Clin Oncol 2013, 31:876-885.

44. Martinez-Gomez D, Guallar-Castillón P, León-Munoz LM, López-Garcia E, Rodríguez-Artalejo F: Combined impact of traditional and non-traditional health behaviors on mortality: a national prospective cohort study in Spanish older adults. BMC Med 2013, 22:47.

45. Pavey TG, Peeters GG, Brown WJ: Sitting-time and 9-year all-cause mortality in older women. Br J Sports Med 2012, 0:1-5

46. León-Muñoz LM, Martínez-Gómez D, Balboa-Castillo T, López-García E, Guallar-Castillón P, Rodríguez-Artalejo F: Continued sedentariness, change in sitting time, and mortality in older adults. Med Sci Sports Exerc 2013, 45:1501-1507

47. Verghese J, Lipton RB, Katz MJ, Hall CB, Derby CA, Kuslansky G, Mabrose AF, Sliwinski M, Buschke $\mathrm{H}$ : Leisure Activities and the Risk of Dementia in the Elderly. N Engl J Med 2003, 348:2508-2516.

48. Proper Kl, Singh AS, Van Mechelen W, Chinapaw MJ: Sedentary behaviors and health outcomes among adults: a systematic review of prospective studies. Am J Prev Med 2011, 40:174-182.

49. Atkin AJ, Gorely T, Clemes SA, Yates T, Edwardson C, Brage S, Salmon J, Marshall SJ, Biddle SJH: Methods of measurement in epidemiology: sedentary behaviour. Int J Epidemiol 2012, 41:1460-1471.

50. Gabriel KKP, Morrow JR, Woolsey AL: Framework for physical activity as a complex and multidimensional behavior. J Phys Act Health 2012, 9(Suppl 1):S11-S18.
51. Anguera JA, Boccanfuso J, Rintoul JL, Al-Hashimi O, Faraji F, Janowich J, Kong E, Larraburo Y, Rolle C, Johnston E, Gazzaley A: Video game training enhances cognitive control in older adults. Nature 2013, 5:97-101.

52. Kueider AM, Parisi JM, Gross AL, Rebok GW: Computerized cognitive training with older adults a systematic review. PLoS One 2012, 7:e40588.

53. Primack BA, Carroll MV, McNamara M, Klem ML, King B, Rich M, Chan CW, Nayak S: Role of video games in improving health-related outcomes: a systematic review. Am J Prev Med 2012, 42:630-638.

54. Wong SL, Colley R, Connor Gorber S, Tremblay M: Actical accelerometer sedentary activity thresholds for adults. J Phys Act Health 2011, 8:587-591.

55. Hart TL, Swartz AM, Cashin SE, Strath SJ: How many days of monitoring predict physical activity and sedentary behaviour in older adults? Int J Behav Nutr Phys Act 2011, 8:62.

56. Mâsse LC, Fuemmeler BF, Anderson CB, Matthews CE, Trost SG, Catellier DJ, Treuth M: Accelerometer data reduction: a comparison of four reduction algorithms on select outcome variables. Med Sci Sports Exerc 2005, 37:S544-S554.

57. Kozey-Keadle S, Libertine A, Lyden K, Staudenmayer J, Freedson PS: Validation of wearable monitors for assessing sedentary behavior. Med Sci Sports Exerc 2011, 43:1561-1567.

58. Yudkin J, Lipska K, Montori V: The idolatry of the surrogate. BMJ 2011, 343:d7995

59. Andrade C, Fernandes $P$ : Is sitting harmful to health? It is too early to say. Arch Int Med 2012, 172:1272.

60. Dinero TE: Seven reasons why you should not categorize continous data. J Health Soc Policy 1996, 8:63-72.

61. Altman D, Royston P: The cost of dichotomisng continous variables. BMJ 2006, 332:1080.

doi:10.1186/1471-2458-14-333

Cite this article as: Rezende et al: Sedentary behavior and health outcomes among older adults: a systematic review. BMC Public Health 2014 14:333.

\section{Submit your next manuscript to BioMed Central and take full advantage of:}

- Convenient online submission

- Thorough peer review

- No space constraints or color figure charges

- Immediate publication on acceptance

- Inclusion in PubMed, CAS, Scopus and Google Scholar

- Research which is freely available for redistribution

Submit your manuscript at www.biomedcentral.com/submit
C) Biomed Central 